\title{
EDITORIAL
}

\section{Concurrent allergic bronchopulmonary aspergillosis and aspergilloma: is it a more severe form of the disease?}

\author{
A. Shah
}

$\mathbf{T}$ he mould Aspergillus, a genus of spore forming fungi, affects the respiratory system in more ways than one. The clinical spectrum of Aspergillus involvement of the lungs ranges from various hypersensitivity manifestations to invasive disease which can be fatal. The inhaled spores hardly affect healthy persons but in asthmatic subjects these spores are trapped in the viscid secretions found in the airways. Repeated inhalation of Aspergillus antigens triggers allergic reactions in atopic individuals, which may manifest as Aspergillus-induced asthma, allergic bronchopulmonary aspergillosis (ABPA) and allergic Aspergillus sinusitis (AAS) [1]. Saprobic colonisation of airways, cavities and necrotic tissue leads to the development of aspergillomas.

Although ABPA is predominantly a disease of asthmatics, only a few asthmatics actually suffer from it. Contemporary reports suggest that ABPA occurs in up to $11 \%$ of patients with asthma [2-6]. The variable prevalence rates of ABPA in asthma may be attributable to the lack of a single diagnostic criterion and standardised tests [7]. A set of eight major and three minor criteria for the diagnosis of ABPA has evolved over time but minimal essential criteria have been identified: 1 ) asthma; 2 ) immediate cutaneous reactivity to A. fumigatus; 3 ) total serum immunoglobulin (Ig)E $>1,000 \mathrm{ng} \cdot \mathrm{mL}^{-1}$; 4) elevated specific IgE- $A f / \operatorname{IgG}-A f$; and 5) central bronchiectasis in the absence of distal bronchiectasis [8].

This 'picturesque' disease causes a wide spectrum of chest radiographic appearances, which could be either transient or permanent [9]. The most characteristic transient changes are "fleeting opacities" or transient pulmonary infiltrates while the most pathognomonic permanent feature is the occurrence of central bronchiectasis with normal peripheral bronchi [10]. Cavitation, though not a common feature of ABPA, has been reported in $3-14 \%$ of patients [11-13].

Aspergillomas or fungal balls, due to Aspergillus species, form in pre-existing cavities and are most commonly found in healed tuberculous cavities [14]. Other cystic and cavitating

CORRESPONDENCE: A. Shah, Dept of Respiratory Medicine, Vallabhbhai Patel Chest Institute, University of Delhi, P.0. Box 2101, Delhi 110 007, India. E-mail: ashokshah99@yahoo.com

Received: Sept 22 2010; Accepted: Sept 272010

PROVENANCE: Submitted article, peer reviewed. lung diseases in which aspergilloma formation has been reported include sarcoidosis [15], hydatidosis [16], pneumatocoele caused by Pneumocystis pneumonia [17], bronchiectasis, emphysematous bullae, and sites of prior lobectomies or pneumonectomies. The time required for the development of fungal balls ranges from a few months to more than 10 yrs [18].

The clinical categories of Aspergillus-related respiratory disorders, for reasons unknown, usually remain mutually exclusive. In spite of similar immunopathological responses, concomitant occurrence of ABPA and AAS is infrequently reported [19-22]. In this issue of the European Respiratory Review, MONTANI et al. [23] describe a 50-yr-old female with concomitant ABPA and aspergilloma. Even though chronic lung damage appears to provide a favourable milieu for aspergilloma formation, the concomitant occurrence of aspergillomas is rather uncommon in patients with ABPA, even in the presence of cavitation [24, 25].

From 1956 to 1980, JEWKES et al. [26] analysed 85 patients with pulmonary aspergilloma and showed that type 1 hypersensitivity to A. fumigatus skin testing was positive in 39 (70\%) of the 56 patients tested, but symptoms of asthma were present in 22 and pre-existing ABPA was evident in only 10 patients. In a study of 28 patients with pulmonary aspergilloma described by MCCARTHY and PEPYS [27], immediate hypersensitivity to $A$. fumigatus was demonstrated in 21 subjects, 12 of whom had asthma. 10 of these 12 subjects had ABPA. This is the only study that has demonstrated such a high occurrence of ABPA and aspergilloma.

The temporal relationship between ABPA and aspergilloma is not clearly defined. The appearance of aspergilloma prior to or consequent to ABPA has been documented. In six of the 10 patients with ABPA described earlier [27], aspergilloma formation happened many years after the diagnosis of ABPA was established. In the six patients of ABPA with aspergilloma documented by us $[20,24,25,28,29]$, aspergillomas formed in pre-existing cavities in patients with ABPA. The manifestation of ABPA subsequent to aspergilloma formation has also been recorded [27, 30]. It was postulated that an aspergilloma may function as a nidus for antigenic stimulation in a genetically predisposed individual, thus leading to ABPA [30]. In four of the 10 patients studied by MCCARTHY and PEPYS [27], fungal balls were present a number of years before ABPA could be diagnosed. The authors speculated that these patients could 
possibly have been sensitised to Aspergillus antigens released from the aspergilloma.

In a background of cavitary lung disease occurring due to ABPA, formation of an aspergilloma might be accelerated by corticosteroid therapy [24, 28]. All of the 10 patients with ABPA and aspergilloma described by JEWKES et al. [26] were treated with corticosteroids and the size of the aspergilloma increased in two patients. It has been postulated that the use of corticosteroids in patients with ABPA with cavitary disease may predispose them to aspergilloma formation and invasive aspergillosis. In two of the six patients with coexistent ABPA and aspergilloma reported by us, evolution of aspergilloma occurred after initiation of corticosteroids [24, 28]. One of them, a 42-yr-old male, developed an ovoid density in the inferior margin of the pre-existing cavity after starting corticosteroid therapy, with which remission was achieved. The patient suffered an exacerbation after 3 yrs in remission state although he had radiological evidence of the fungal ball [31]. The second patient, a 20-yr-old female, developed an aspergilloma 2 yrs after receiving corticosteroid therapy for ABPA [28]. Rapid development of an aspergilloma within a 2-month period was reported in a 47-yr-old female who had cavitary disease for 7 yrs due to tuberculosis. This occurred after she was prescribed corticosteroids for pulmonary-renal syndrome due to systemic vasculitis [32].

The association of ABPA, AAS and aspergilloma in the same patient has been documented only twice to date [20, 29]. The first patient initially developed an aspergilloma in a bronchiectatic cavity, for which she underwent left lower lobectomy in view of severe haemoptysis [20]. The diagnosis of ABPA and AAS was made subsequently when she presented with collapse of the left lung and associated pleural effusion. In our second patient, all the three clinical entities, ABPA, AAS and aspergilloma, were diagnosed concurrently when he presented to us for evaluation of progressive respiratory symptoms [29]. In this patient, the fungal ball was no longer visible on a follow-up computed tomography scan at $3.5 \mathrm{yrs}$, after maintenance therapy with repeated courses of prednisolone.

Management of coexistent ABPA and aspergilloma could pose a dilemma due to the constant risk of aggravation with corticosteroids. Antifungal agents, especially itraconazole could possibly be offered as an adjunct therapy to oral corticosteroids. A reduction in Aspergillus colonisation of the airways in ABPA has been noted with itraconazole. The patient reported in this issue of the European Respiratory Review responded well to wedge resection of the aspergilloma and itraconazole post-operatively [23]. A significant reduction in the total IgE level was noted at 5 months and itraconazole was discontinued after 1.5 yrs. The patient continued to remain asymptomatic at 2 yrs. However, itraconazole is yet to emerge as the mainstay of therapy.

When ABPA and aspergilloma ensue together, the severity of the disease is likely to increase. Not only will this cause loss of control of asthma, but also increases the risk of life-threatening complications like haemoptysis and invasive disease. It would be prudent to closely monitor all patients with ABPA with cavitation, when initiated on systemic corticosteroids.

\section{STATEMENT OF INTEREST}

None declared.

\section{REFERENCES}

1 Shah A, Panjabi C. Allergic bronchopulmonary aspergillosis: a review of a disease with a worldwide distribution. J Asthma 2002; 39: $273-289$

2 Henderson AH, English MP, Vecht RJ. Pulmonary aspergillosis: a survey of its occurrence in patients with chronic lung disease and a discussion of the significance of diagnostic tests. Thorax 1968; 23: 513-518.

3 Greenberger PA, Patterson R. Allergic bronchopulmonary aspergillosis and the evaluation of the patient with asthma. J Allergy Clin Immunol 1988; 81: 646-650.

4 Donnelly SC, McLaughlin H, Bredin CP. Period prevalence of allergic bronchopulmonary mycosis in a regional hospital outpatient population in Ireland 1985-1988. Irish J Med Sci 1991; 160: 288-290.

5 Eaton T, Garrett J, Milne D, et al. Allergic bronchopulmonary aspergillosis in the asthma clinic: a prospective evaluation of $\mathrm{CT}$ in the diagnostic algorithm. Chest 2000; 118: 66-72.

6 Maurya V, Gugnani HC, Sarma PU, et al. Sensitization to Aspergillus antigens and occurrence of allergic bronchopulmonary aspergillosis in patients with asthma. Chest 2005; 127: 1252-1259.

7 Shah A. Allergic bronchopulmonary aspergillosis: a view from India. Saudi Med J 2002; 23: 1559-1561.

8 Greenberger PA. Allergic bronchopulmonary aspergillosis. J Allergy Clin Immunol 2002; 110: 685-692.

9 Shah A. Allergic bronchopulmonary and sinus aspergillosis: the roentgenologic spectrum. Front Biosci 2003; 8: e138-e146.

10 Scadding JG. The bronchi in allergic aspergillosis. Scand J Respir Dis 1967; 48: 372-377.

11 McCarthy DS, Simon G, Hargeave FE. The radiological appearances in allergic bronchopulmonary aspergillosis. Clin Radiol 1970; 21: 366-375.

12 Phelan MS, Kerr IH. Allergic bronchopulmonary aspergillosis: the radiological appearances during long-term follow up. Clin Radiol 1984; 35: 385-392.

13 Shah A, Panchal N, Panjabi C. Allergic bronchopulmonary aspergillosis: a review from India. Allergy Clin Immunol Int 2003; 1: Suppl., 104.

14 British Thoracic and Tuberculosis Association. Aspergilloma and residual tuberculosis cavities. The results of a re-survey. Tubercle 1970; 51: 227-245.

15 Panjabi C, Sahay S, Shah A. Aspergilloma formation in cavitating sarcoidosis. J Bras Pneumol 2009; 35: 480-483.

16 M'saad S, Ayedi L, Abdennader M, et al. Aspergilloma in a hydatid cavity. Respir Med 2010; 3: 29-32.

17 Schouwink JH, Weigel HM, Blaauwgeers JL, et al. Aspergilloma formation in a pneumatocele associated with Pneumocystis carinii pneumonia. AIDS 1997; 11: 135-137.

18 Kurashima A. Analysis of the course of non-invasive pulmonary aspergillosis. Jpn J Med Mycol 1997; 38: 167-174.

19 Shah A, Khan ZU, Chaturvedi S, et al. Concomitant allergic Aspergillus sinusitis and allergic bronchopulmonary aspergillosis associated with familial occurrence of allergic bronchopulmonary aspergillosis. Ann Allergy 1990; 64: 507-512.

20 Bhagat R, Shah A, Jaggi OP, et al. Concomitant allergic bronchopulmonary aspergillosis and allergic Aspergillus sinusitis with an operated aspergilloma. J Allergy Clin Immunol 1993; 91: 1094-1096.

21 Shah A, Bhagat R, Panchal N, et al. Allergic bronchopulmonary aspergillosis with middle lobe syndrome and allergic Aspergillus sinusitis. Eur Respir J 1993; 6: 917-918. 
22 Shah A, Panchal N, Agarwal AK. Concomitant allergic bronchopulmonary aspergillosis and allergic Aspergillus sinusitis: a review of an uncommon association. Clin Exp Allergy 2001; 31: 1896-1905.

23 Montani D, Zendah I, Achouh L, et al. Association of pulmonary aspergilloma and allergic bronchopulmonary aspergillosis. Eur Respir Rev 2010; 19: 349-351.

24 Shah A, Khan ZU, Chaturvedi S, et al. Allergic bronchopulmonary aspergillosis with co-existent aspergilloma: a long term follow up. J Asthma 1989; 26: 109-115.

25 Agarwal AK, Bhagat R, Panchal N, et al. Allergic bronchopulmonary aspergillosis with aspergilloma mimicking fibrocavitary pulmonary tuberculosis. Asian Pac J Allergy Immunol 1996; 14: 5-8.

26 Jewkes J, Kay PH, Paneth M, et al. Pulmonary aspergilloma: analysis of prognosis in relation to haemoptysis and survey of treatment. Thorax 1983; 38: 572-578.

27 McCarthy DS, Pepys J. Pulmonary aspergilloma: clinical immunology. Clin Allergy 1973; 3: 57-70.
28 Sharma P, Agarwal AK, Shah A. Formation of an aspergilloma in a patient with allergic bronchopulmonary aspergillosis on corticosteroid therapy. Indian J Chest Dis Allied Sci 1998; 40: 269-273.

29 Shah A, Panjabi C. Contemporaneous occurrence of allergic bronchopulmonary aspergillosis, allergic Aspergillus sinusitis and aspergilloma. Ann Allergy Asthma Immunol 2006; 96: 874-878.

30 Ein ME, Wallace RJ Jr, Williams TW. Allergic bronchopulmonary aspergillosis-like syndrome consequent to aspergilloma. Am Rev Respir Dis 1979; 119: 811-820.

31 Shah A, Bhagat R, Pant K, et al. Allergic bronchopulmonary aspergillosis with aspergilloma: excaberation after prolonged remission. Indian J Tuberc 1993; 40: 39-41.

32 Akimoto T, Saito O, Inoue M, et al. Rapid formation of Aspergillus mycetoma in a patient receiving corticosteroid treatment. Serial radiographic observation over two months. Intern Med 2007; 46: 733-738. 